\title{
Wind energy potential estimation for different regions of Bangladesh
}

\author{
Proma Anwar Khan ${ }^{1}$, Pobitra Kumar Halder ${ }^{2, ~ *, ~ S a b b i r ~ R a h m a n ~}{ }^{1}$ \\ ${ }^{1}$ Department of Mechanical Engineering, Bangladesh University of Engineering and Technology, Dhaka-1000, Bangladesh \\ ${ }^{2}$ Department of Industrial and Production Engineering, Jessore University of Science and Technology, Jessore-7408, Bangladesh
}

\section{Email address:}

proma_a@yahoo.com (P. A. Khan), pobitra.halder@gmail.com (P. K. Halder), sabbirrahman_rajib@yahoo.com (S. Rahman)

\section{To cite this article:}

Proma Anwar Khan, Pobitra Kumar Halder, Sabbir Rahman. Wind Energy Potential Estimation for Different Regions of Bangladesh. International Journal of Renewable and Sustainable Energy. Vol. 3, No. 3, 2014, pp. 47-52. doi: 10.11648/j.ijrse.20140303.11

\begin{abstract}
This paper deals with the estimation of available wind energy potential in Bangladesh and how it can be utilized. The natural sources of energy are limited. Wind is a very good source of energy in many countries of the world. It is a renewable source of energy that can be used in electricity generation, pumping water and many other sectors. But in our country wind energy extraction is a bit difficult due to low wind speed. In this paper, the available wind energy in Rangamati, Bandarban and Teknaf of our country is calculated both hourly basis. Three stations are analyzed in terms of established parameters like Weibull distribution of wind data, frequency distribution of wind directions over few years using measured data collected from Bangladesh Meteorological Department (BMD). The predictions and calculations of wind potentials are performed for commercial turbine altitudes $50-70 \mathrm{~m}$ to overcome the limitations of the weather data obtained by meteorological anemometers at lower heights. This analysis can also show the variation in wind energy in different seasons. It can help us to understand how much energy we have and how much energy can be fruitfully utilized.
\end{abstract}

Keywords: Wind Regime, Wind Potential, Weibull Distribution

\section{Introduction}

Wind is the response of the atmosphere arises due to uneven heating condition of the earth which produces a pressure difference in the atmosphere triggering the wind to blow from high pressure regions to low pressure regions. The wind velocity is greatly depended on the pressure difference as the larger the pressure difference enhances the wind velocity. Air pressure represents the amount of atmosphere that is pressing down on the surface of the earth at some point. Actually wind is a form of solar energy and is generated due to the uneven heating of the atmosphere by the sun, the irregularities of the earth's surface, and rotation of the earth. The earth's terrains, bodies of water, vegetative cover are the factors used to modify the wind flow patterns [1]. This motion energy of wind can be harvested by modern wind turbines to generate electricity. The demand for energy is increasing day by day in the whole world as well as in Bangladesh due to rapid depletion of non-renewable energy like fossil fuels, oils and natural gases [2]. Every year the demand increases $6 \%$ to $7 \%$ in Bangladesh. The per capita consumption of energy in our country is about $1 / 10$ th of the world and $1 / 4$ th of the Asian average. Thus, renewable energy source is necessary to meet this increasing energy demand. Wind energy is one form of new and renewable energy and appropriate extraction can contribute significantly to our national energy supply. Another important aspect is that, the pollution and emission from conventional energy and this rise to greenhouse effect and acid rain with adverse consequences for health and climate. Wind energy is a very clean and environmentally renewable energy [3]. Therefore, it is right time to explore and implement the wind energy technology without any further delay. Considering the wind speed characteristic it is believed that wind energy has a bright prospect and significantly towards the solution of energy crisis in Bangladesh.

\section{Wind Characteristics}

Wind speed is always fluctuating due to variation air pressure between two regions, Coriolis force, the surface friction; thus the energy content of the wind is always changing. In general, the magnitude of the variation depends on the weather, local surface conditions, and obstacles [4]. It is necessary to understand a good 
knowledge of wind speed in the regions ranging from $10-120 \mathrm{~m}$ above the terrain surface to install the wind generator. Unfortunately, in most cases these data are not available; thus using appropriate expressions estimations are made. The surface roughness of the earth slowdowns the wind near the ground and produces the so-called Atmospheric Boundary Layer (ABL) which is mainly affected by wind speed and surface roughness and varies from a few hundred to about $4000 \mathrm{~m}$ thick [5]. The shape of the velocity profile is quite well established from measurements over the ground. It is dependent on the surface roughness, and thermal effects due to heating of the ground. However, the significant mixing of the air over the sea reduces the thermal effects to a negligible amount [5]. The surface roughness and mean wind speed totally determine the flow characteristics, or wind structure.

Deaves and Harris have developed a mathematical model of the $\mathrm{ABL}$ considering the $\mathrm{ABL}$ as in equilibrium for wind engineering application purpose [6]. The expression for the velocity profile is given as:

$$
\begin{gathered}
\frac{V}{V^{*}}=\frac{1}{k}\left[\ln \left(\frac{z}{z_{o}}\right)+\xi\left(\frac{z}{z_{g}}\right)\right] \\
\frac{V}{V^{*}}=\frac{1}{k}\left[\ln \left(\frac{z}{z_{o}}\right)+a_{1}\left(\frac{z}{z_{g}}\right)+a_{1}\left(\frac{z}{z_{g}}\right)^{2} \cdots \cdots \cdots+a_{n}\left(\frac{z}{z_{g}}\right)^{n}\right]
\end{gathered}
$$

Where, $k=0.4$.

The function $\left(z / Z_{o}\right)$ is determined by the solar radiation at the specified zone. In strong wind speed conditions, $Z g$ typically is $2000 \mathrm{~m}$, and since the most height of a $12 \mathrm{~m}$ hatchet is about $26-30 \mathrm{~m}$, the sails operate in a very small fraction of the ABL. Thus the equation is expressed as:

$$
\frac{V}{V^{*}}=\frac{1}{k} \ln \left(\frac{z}{z_{o}}\right)
$$

The mean surface roughness $Z_{0}$ will depend on the size and distance between the objects selected to determine the roughness, such as grass, building, trees, etc. $Z_{0}$ is a function of the size of the roughness elements and expressed as

$$
\begin{aligned}
Z_{o} & =10 e^{-(0.4 / k)} \\
k & =10^{-4}(7.5+0.67 \mathrm{~V})
\end{aligned}
$$

\section{Study Area}

To make proper use of wind energy, proper site selection and wind speed availability are to be considered first. The wind speed and its duration are the key factors to design and to determine the use of wind energy. Therefore, to generate accurate and more reliable wind speed data, the wind speed data monitoring system must be carried out before going to take any plan to implement either comprehensive or pilot plant in this regard. With a view to evaluating the actual pattern of wind energy, a typical location is chosen and wind speed is continuously monitored. For this, wind data of
Rangamati, Bandarban and Teknaf were analysed as shown in Figure 1 [7].

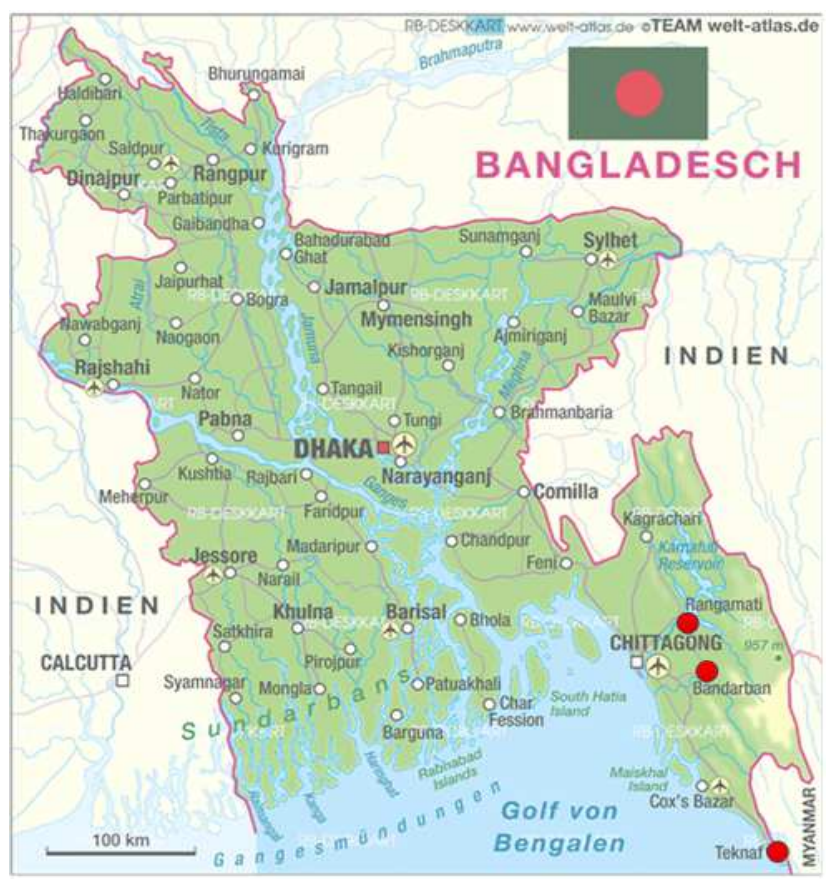

Fig. 1.Study location in Bangladesh

\section{Wind Data Analysis and Potential Estimation}

\subsection{Data Collection and Processing}

From wind data and observations, frequency distributions, speed durations; mean wind speed of month or year, Weibull distribution, energy potential may be projected.

\subsubsection{Frequency Distribution}

The frequency distribution of wind speeds i.e. the number of hours per month or per year during which the wind speeds occur is very essential for potential estimation [8]. In order to get this frequency distribution the wind speed domain is divided into a number of equal intervals of $1 \mathrm{~m} / \mathrm{s}$ or $0.5 \mathrm{~m} / \mathrm{s}$ [9]. From the first interval of $0-1 \mathrm{~m} / \mathrm{s}$, the number of hours is counted in the period ensuring the wind speed was in this interval. This velocity frequency distribution as relative frequency is obtained from the velocity interval. The velocity intervals are $1 \mathrm{~m} / \mathrm{s}$ wide such as $0-1,1-2,2-3 \ldots . \mathrm{m} / \mathrm{s}$. All the velocities above $15 \mathrm{~m} / \mathrm{s}$ have been considered under $12-13 \mathrm{~m} / \mathrm{s}$ class interval. The frequency distribution of Teknaf is shown in Table 1.

Table 1. Velocity frequency (hour basis) for Teknaf, March 2003

\begin{tabular}{lll}
\hline Speed $(\mathbf{m} / \mathbf{s})$ & $\begin{array}{l}\text { Total hours of the } \\
\text { month }(\%)\end{array}$ & $\begin{array}{l}\text { Frequency distribution } \\
\text { (hrs.) }\end{array}$ \\
\hline $0-1$ & 3.22 & 23 \\
$1-2$ & 11.32 & 85 \\
$2-3$ & 23.05 & 179 \\
$3-3$ & 22.71 & 169 \\
$3-5$ & 15.72 & 117 \\
\hline
\end{tabular}




\begin{tabular}{lll}
\hline Speed $(\mathbf{m} / \mathbf{s})$ & $\begin{array}{l}\text { Total hours of the } \\
\text { month }(\%)\end{array}$ & $\begin{array}{l}\text { Frequency distribution } \\
\text { (hrs.) }\end{array}$ \\
\hline $5-6$ & 11.15 & 83 \\
$6-7$ & 5.63 & 32 \\
$7-8$ & 2.55 & 19 \\
$8-9$ & 2.69 & 20 \\
$9-10$ & 0.53 & 5 \\
$10-11$ & 0 & 0 \\
$11-12$ & 0 & 0 \\
$12-13$ & 0.13 & 1 \\
\hline
\end{tabular}

\subsubsection{Data Processing for Weibull Distribution}

This frequency distribution is further processed for Weibull Distribution to have the shape/form factor $(\mathrm{k})$ and scale factor (c). There are many distributions to analyze any raw data. However, for the wind regime Weibull Distribution fits very closely due to its flexibility in nature [10]. Depending on the value of $\mathrm{k}$, the Weibull Function becomes Normal Distribution, Raleigh Distribution and exponential one. It is one of the most powerful tools to analyze wind regime for any site. At first the hourly frequency distribution is added successively to have a cumulative frequency distribution. Then this value of individual velocity class is divided by total time (733 or 720 hrs.). The frequency distribution will be used to calculate the energy output of windy sites by multiplying the number of hours in each interval with the power output as the equation is presented in Table 2 .

It is the rule of wind energy equation. Similar calculations have been done for each location. The data of this processed table is used to analysis the whole system of wind monitoring parameters. From all the processed data, the location wise frequency distribution of wind speeds can be drawn easily.

Table 2. Data processing for Weibull Distribution from the raw data

\begin{tabular}{|c|c|c|c|c|c|c|c|c|}
\hline $\begin{array}{l}\text { Interval, } \\
\text { V (m/s) }\end{array}$ & $\begin{array}{l}\text { Frequency, } \\
\text { h }_{\mathrm{i}} \text { (hrs.) }\end{array}$ & $\begin{array}{l}\text { Relative } \\
\text { frequency, } \\
\mathbf{h}_{\mathrm{i}} / \mathrm{T}\end{array}$ & $\begin{array}{l}\text { Cumulative } \\
\text { frequency, } \\
\sum \mathbf{h}_{\mathrm{i}}\end{array}$ & $\begin{array}{l}\text { Relative } \\
\text { cumulative } \\
\text { frequency, } \sum \mathbf{h}_{\mathrm{i}} / \mathbf{T}\end{array}$ & $\begin{array}{c}\text { Velocity } \\
\text { Duration, } \\
\mathbf{T}-\mathbf{h}_{\mathbf{i}}\end{array}$ & $\begin{array}{l}\text { Relative } \\
\text { velocity duration, } \\
1-\mathbf{f}(\mathbf{v})\end{array}$ & $\begin{array}{l}\text { Velocity } \\
(\mathrm{m} / \mathrm{s})\end{array}$ & $\begin{array}{l}\text { Energy, } \\
E=0.1 v^{3} h_{i} \\
\left(W h / \mathbf{m}^{2}\right)\end{array}$ \\
\hline $0-1$ & 23 & 0.031378 & 23 & 0.031378 & 710 & 0.968622 & 0.5 & 0.2875 \\
\hline $1-2$ & 85 & 0.115962 & 108 & 0.14734 & 648 & 0.884038 & 1.5 & 28.6875 \\
\hline $2-3$ & 179 & 0.244202 & 287 & 0.391542 & 554 & 0.755798 & 2.5 & 279.6875 \\
\hline $3-4$ & 169 & 0.230559 & 456 & 0.622101 & 564 & 0.769441 & 3.5 & 724.5875 \\
\hline $4-5$ & 117 & 0.159618 & 573 & 0.781719 & 616 & 0.840382 & 4.5 & 1066.163 \\
\hline $5-6$ & 83 & 0.113233 & 656 & 0.894952 & 650 & 0.886767 & 5.5 & 1380.913 \\
\hline $6-7$ & 32 & 0.043656 & 688 & 0.938608 & 701 & 0.956344 & 6.6 & 919.9872 \\
\hline $7-8$ & 19 & 0.025921 & 707 & 0.964529 & 714 & 0.974079 & 7.5 & 801.5625 \\
\hline $8-9$ & 20 & 0.027285 & 727 & 0.991814 & 713 & 0.972715 & 8.5 & 1228.25 \\
\hline $9-10$ & 5 & 0.006821 & 732 & 0.998636 & 728 & 0.993179 & 9.5 & 428.6875 \\
\hline $10-11$ & 0 & 0 & 732 & 0.998636 & 733 & 1 & 10.5 & 0 \\
\hline $11-12$ & 0 & 0 & 732 & 0.998636 & 733 & 1 & 11.5 & 0 \\
\hline $12-13$ & 1 & 0.001364 & 733 & 1 & 732 & 0.998636 & 12.5 & 195.3125 \\
\hline
\end{tabular}

\subsection{Mathematical Representation of Wind Regimes}

After data processing it has been found that, if the wind speed values are made dimensionless, by dividing them by the average wind speed of that particular distribution much attention has been given to the Weibull function, since it is a good match with the experimental data. In some cases the Raleigh Distribution, a special case of the Weibull Distribution, is preferred. This section deals with the Weibull Function and the method to estimate its parameters from a given distribution.

\subsubsection{The Weibull Distribution}

TheWeibull distribution is characterized by two parameters as the shape parameter $\mathrm{k}$ (dimensionless) and the scale parameter $\mathrm{c}(\mathrm{m} / \mathrm{s})$ and the cumulative distribution function is given by [11],

$$
F(v)=1-e^{-\left(\frac{v}{c}\right)^{k}}
$$

Moreover, the Weibull density (provability density) function is given by [10],

$$
f(v)=\frac{d F(v)}{d v}=\left(\frac{k}{c}\right)\left(\frac{v}{c}\right)^{k-1} e^{-\left(\frac{v}{c}\right)^{k}}
$$

With an expression of Gamma function $\Gamma(\mathrm{x})$, the average wind speed can be expressed as a function of $\mathrm{c}$ and $\mathrm{k}$ or vice versa and $\mathrm{c}$ is a function of wind speed, $\mathrm{v}(\mathrm{m} / \mathrm{s})$ and $\mathrm{k}$. The integral found cannot be solved however; it can be reduced to a standard integral, the so-called gamma function [12].

$$
\Gamma(x)=\int_{0}^{a} y^{x-1} e^{-y} d y
$$

With $y=\left(\frac{v}{c}\right)^{k}$ and $\frac{v}{c}=y^{x-1}$

One obtains $x=1+1 / k$ and after a few manipulation,

$$
\begin{array}{r}
V=C \times \Gamma(1+1 / k)= \\
0.8525+0.0135 k+e^{-[2.0+3.0(k-1)]}
\end{array}
$$

This formula can easily be handled by pocket calculators in energy output calculations. The accuracy of the approximation is within $0.5 \%$ for $1.6<k<3.5$.

\subsubsection{Estimation of the Weibull Parameters from the Processed Data}

TheWeibull distribution shows its usefulness when the wind data of reference station are being used to predict the wind regime in the surrounding of that station. The complete frequency distribution of the year or the month is expected only by annual or monthly average wind [13]. In this section the methods to extract the Weibull parameter $\mathrm{k}$ 
and $\mathrm{c}$ from a given set of data is presented. There are several methods by which $\mathrm{k}$ and $\mathrm{c}$ can be determined. Three different methods are shown below.

$\checkmark \quad$ Weibull paper/ Regression analysis

$\checkmark$ Standard-deviation analysis

$\checkmark \quad$ Energy pattern factor analysis

Among the three methods mention above, energy pattern factor analysis method is used for determining the values of $\mathrm{k}$ and $\mathrm{c}$. The energy pattern factor of a given set of $\mathrm{N}$ hourly data $V_{n}$ can be determined with the following equation [14],

$$
k_{E}=\frac{\frac{1}{N} \sum_{n=1}^{N} V_{n}{ }^{3}}{\left(\frac{1}{N} \sum_{n=1}^{N} V_{n}\right)^{3}}
$$

Using the above expression the Weibull shape parameter $\mathrm{k}$ is easily found. Value of $\mathrm{k}$ and $\mathrm{c}$ by this method for each station for each month is determined and is given in Table 3 .

Table 3. Closest values of $k$ and $c$

\begin{tabular}{ccccccc}
\hline \multirow{2}{*}{ Months } & \multicolumn{2}{c}{ Rangamati } & \multicolumn{2}{c}{ Bandarban } & \multicolumn{2}{c}{ Teknaf } \\
& $\mathbf{k}$ & $\mathbf{c}$ & $\mathbf{k}$ & $\mathbf{c}$ & $\mathbf{k}$ & $\mathbf{c}$ \\
\hline March & 1.80 & 3.30 & ---- & ---- & 1.35 & 3.13 \\
April & 1.21 & 5.50 & 1.13 & 8.73 & 1.62 & 2.86 \\
May & 2.20 & 3.39 & 1.38 & 2.50 & 1.55 & 2.65 \\
June & 2.15 & 3.05 & 2.10 & 3.15 & 1.99 & 5.37 \\
July & 2.70 & 3.82 & 2.10 & 6.13 & 1.63 & 3.19 \\
August & 1.87 & 3.81 & 1.30 & 3.87 & 1.97 & 3.68 \\
September & 1.33 & 2.22 & 2.17 & 5.86 & 1.83 & 3.38 \\
\hline
\end{tabular}

After determining the parameters of Weibull Function, the calculated Weibull density Function $f(v)$, Weibull Function F (v) and Velocity Duration Function S (v) are checked with the observed data.

\subsection{Wind Energy Potential}

The wind energy potential is the power available from the kinetic energy of the mass of air moving in wind. The amount of energy that the wind carries increase by a factor of two as its speed increases. It is also proportional to the density and the area through which wind passes [15]. Mathematical expression for wind potential estimation is given as wind potential, $\mathrm{P}=1 / 2 \times \rho \times A \times V^{3} \mathrm{~W}$. Where, $\rho=$ air density $\left(\mathrm{kg} / \mathrm{m}^{3}\right) ; A=$ swept area of blades $\left(\mathrm{m}^{2}\right) ; \mathrm{V}=$ velocity of wind $(\mathrm{m} / \mathrm{s})$. Current wind turbines can convert up to $50 \%$ energy into electricity [14]. A wind turbine, if properly designed and located, can supply enough wind energy. The peak rainfall in Bangladesh occurs during the months of June, July and August. But peak wind speeds are available during the hottest and driest months of March, April and May. From September to February the velocities are not sufficient for harnessing power. However, there is wide variation of wind speeds in the coastal areas throughout the year.

The size and shape of the rotor appropriate to a location is determined by the total amount of extracted wind power of that area [16]. Here, the average of the data recorded during the period of April 2003 to August 2003 is analyzed. The average wind velocity in Rangamati, Bandarban and Teknafof Bangladesh for the month of April to August is presented in
Figure 2. The wind power per unit area of approach is proportional to the cube of wind speed [17] and can be expressed as $\mathrm{P}=0.6 \mathrm{AV}^{3} \mathrm{~W}$, where $\mathrm{P} / \mathrm{A}$ is in $\mathrm{W} / \mathrm{m}^{2}$ and $\mathrm{V}$ is in $\mathrm{m} / \mathrm{s}$.
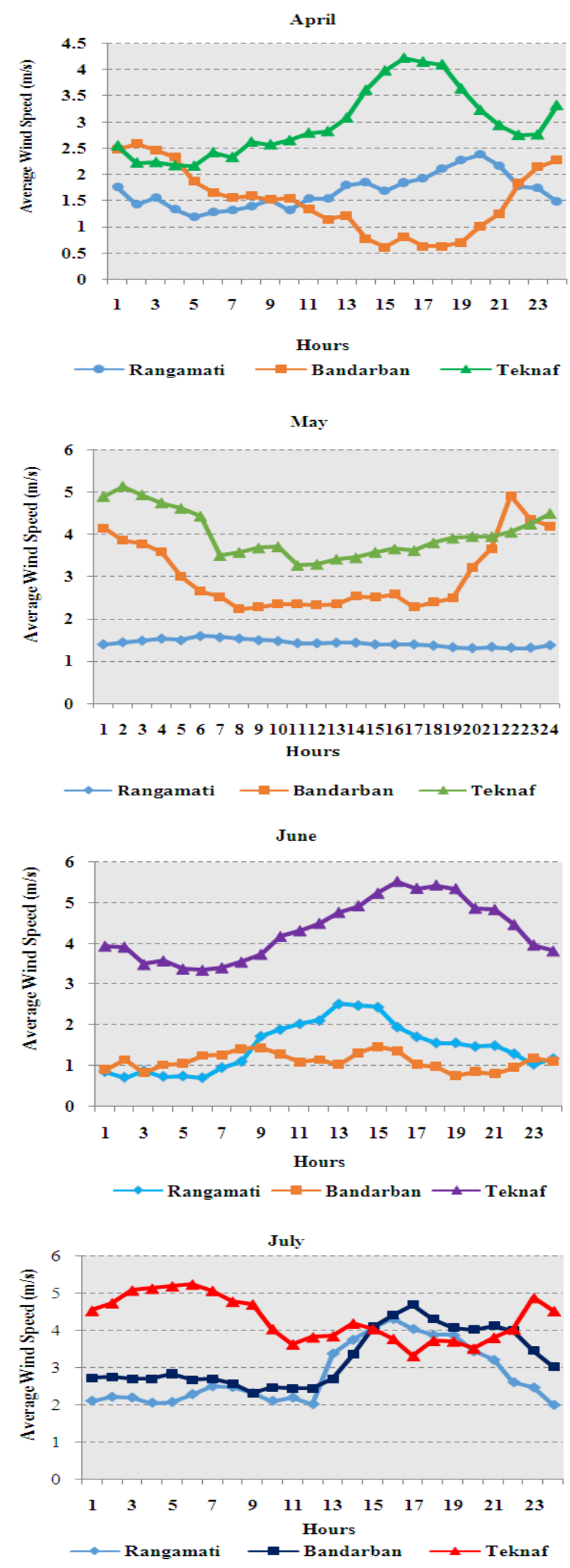


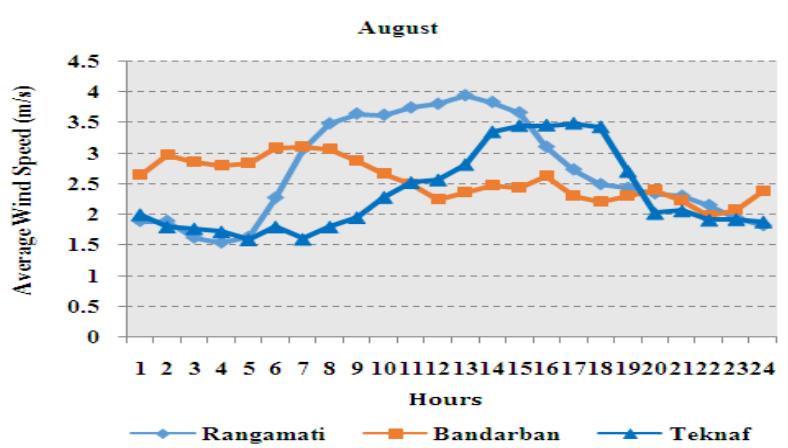

The available wind power signifies the strength of wind and theoretically $59 \%$ of this power is extractable however practically it can be possible to extract only $30-30 \%$ [18]. Table 4 presents an estimation of available wind power in selected location in Bangladesh.Practically, extractable power by any type of windmill can be written approximately as $\mathrm{Pe}=0.1 \mathrm{AV}^{3} \mathrm{~W}$, where $\mathrm{A}$ is the total swept area $\left(\mathrm{m}^{2}\right)$ of the rotor blades and $\mathrm{V}$ is wind speed $(\mathrm{m} / \mathrm{s}), \mathrm{Pe}$ is the practical power (W) [19].In this case, swept area A was not calculated, hence the powerwas estimatedper unit swept area of blade.

Fig. 2. Average wind velocity in selected study area

Table 4. Theoretical available power of selected locations in Bangladesh

\begin{tabular}{ccccc}
\hline Locations & Months & $\begin{array}{c}\text { Average } \\
\text { velocity, } \mathbf{V}(\mathbf{m} / \mathbf{s})\end{array}$ & $\begin{array}{c}\text { Theoreticalavailable } \\
\text { power }\left(\mathbf{W} / \mathbf{m}^{2}\right)\end{array}$ & $\begin{array}{c}\text { Practicalavailable power } \\
\left(\mathbf{W} / \mathbf{m}^{2}\right)\end{array}$ \\
\hline Rangamati & April-August & 2.02 & 4.95 & 0.82 \\
Bandarban & April-August & 2.28 & 7.11 & 1.19 \\
Teknaf & April-August & 3.59 & 27.76 & 4.63 \\
Total & ----- & ----- & 39.82 & 6.64 \\
\hline
\end{tabular}

\section{Conclusion}

Power is the most indispensible requirement for the existence of human being and to improve their lifestyle in the earth. However, Bangladesh has huge shortage of power supply compared to demand. Moreover, utilization of fossil fuel for power generation produces huge environmental pollution. Wind power can be considered in Bangladesh to meet the power demand due to renewability and sustainability though the wind speed is low. Weibull Distribution is used for finding the wind parameters $\mathrm{k}$ and $\mathrm{c}$ in different regions in the country. Maximum k value 2.70 is found in Rangamati in July whereas maximum c value 8.73 is found also in Bandarban in April. Analyzing all the wind data, power is calculated for the region Teknaf, Rangamati, Bandarban and total theoretical power is estimated about $39.82 \mathrm{~W} / \mathrm{m}^{2}$.

\section{Nomenclature}

$\begin{array}{ll}a_{\mathrm{n}} & \text { constant } \\ \mathrm{k} & \text { Vorkarman constant } \\ \mathrm{V} & \text { wind Speed } \\ \mathrm{V}^{*} & \text { friction velocity } \\ \mathrm{Z}_{\mathrm{g}} & \text { the boundary layer height } \\ \mathrm{Z}_{\mathrm{o}} & \text { the roughness length }\end{array}$

\section{References}

[1] Wind Energy. http://gogreenman.com/education/wind energy.htm. (Accessed on May, 2013).

[2] Halder, P. K., Joardder, M. U. H., Beg, M. R. A., Paul, N., \& Ullah, I. (2012). Utilization of bio-oil for cooking and lighting. Advances in Mechanical Engineering, 2012.
[3] Song, Y. D. A new approach for wind speed prediction. Wind Engineering, 24(1), 35-47, 2000.K. Elissa, "Title of paper if known," unpublished.

[4] H. J. Wagner and J.Mathur. Wind: Origin and Local Effects. Introduction to Wind Energy Systems, Green Energy and Technology. pp. 7-16, 2013. DOI: 10.1007/978-3-64232976-02, Springer-Verlag Berlin Heidelberg.

[5] Flay R. G. J., \& Vuletich, I. J. Development of a wind tunnel test facility for yacht aerodynamic studies. Journal of wind engineering and industrial aerodynamics, 58(3), 231-258, 1995.

[6] Cook, N. J. The Deaves and Harris ABL model applied to heterogeneous terrain. Journal of wind engineering and industrial aerodynamics, 66(3), 197-214, 1997.

[7] http://www.welt-atlas.de/map_of_bangladesh_5-766.

[8] Shata, A., \& Shata, A. Theoretical investigation and mathematical modelling of a wind energy system. Case study for Mediterranean and Red Sea (Doctoral dissertation, Universitätsbibliothek), 2008.

[9] De Jongh, J. A., \& Rijs, R. P. P. Wind Resources. World Bank Technical Paper, (101), 2004.

[10] Souvenir Muhammad, Md. Mahbub, Dr. M.A. Rashid Sarker. Analysis of wind energy at BUET. 4th International Conference on Mechanical Engineering, December 26-28, Dhaka, Bangladesh, pp. 119-123, 2001.

[11] Bhattacharya, P. Weibull Distribution for Estimating the Parameters, 2011.

[12] Nearing, J. C. Mathematical Tools for Physics. Dover Publications, 2003.

[13] Azad, A. K., \& Alam, M. M. A Statistical Tools for Clear Energy: Weibull's Distribution for Potentiality Analysis of Wind Energy. International Journal of Advanced Renewable Energy Research, 1, 240-247, 2012. 
[14] Lysen, E.H. Introduction to wind energy: basic and advanced introduction to wind energy with emphasis on water pumping windmills. Amersfoort, The Netherlands: Steering Committee for Wind energy in Developing Countries (SWD), 1982.http://www.arrakis.nl/files/Introduction $\% 20$ to\% 20 Win d\%20Energy\%20E.H.\%20Lysen\%20CWD\%2082-1\%20 may\%201983\%20OCR.pdf.

[15] Wind Energy Technology: An Introduction. http://www. wwindea.org/technology/ch01/en/11.html. (Accessed on May, 2013).

[16] Ahmmed, S., Islam, Q., \& Islam, A. S. A Study of Prospect of Wind Resources for Water Pumpming and Electricity Generation in Bangladesh. ICME-2001.
[17] Mukut, A. M. I., Islam, M. Q., \&Alam, M. M. Analysis of wind characteristics in coastal areas of Bangladesh. Journal of Mechanical Engineering, 39(1), 45-49, 2008.

[18] Sultan, A., and M. Q. Islam. Wind Power for Rural Areas of Bangladesh. 3rd International Conference on Electrical \& Computer Engineering ICECE 2004, 28-30 December 2004, Dhaka, Bangladesh.

[19] Beurskens, H.J.M. Feasibility Study of Windmill for Water Supply in Mara Region, Tanzania. Steering Committee on Wind Energy for Developing Countries, P.O. Box 85, Amersfoort, The Netherlands, 1978. 